\title{
Exercising Market Power in Proprietary Aftermarkets
}

\author{
by \\ Severin Borenstein \\ Jeffrey K. MacKie-Mason \\ Janet S. Netz
}

October 1999

\begin{abstract}
Over 20 recent antitrust cases have turned on whether competition in complex durable equipment markets prevents manufacturers from exercising market power over proprietary aftermarket products and services. We show that the price in the aftermarket will exceed marginal cost despite competition in the equipment market. Absent perfectly contingent long-term contracts, firms will balance the advantages of marginal cost pricing to future generations of consumers against the payoff from monopoly pricing for current, locked-in equipment owners. The result holds for undifferentiated Bertrand competition, differentiated duopoly and monopoly markets. We also examine the effects of market growth and equipment durability.
\end{abstract}

Address. Severin Borenstein: Haas School of Business, University of California, Berkeley, CA 94720-1900, (510) 642-3689, e-mail: borenste@haas.berkeley.edu, and NBER. Jeffrey K. MacKie-Mason: School of Information, Department of Economics, and School of Public Policy, University of Michigan, Ann Arbor, MI 48109-1092, (734) 647-4856, e-mail: jmm@umich.edu. Janet S. Netz: Department of Economics, Purdue University, W. Lafayette, IN 47907-1310, (765) 494-4452, e-mail: netz@purdue.edu. 


\section{Exercising Market Power in Proprietary Aftermarkets}

Severin Borenstein

Jeffrey K. MacKie-Mason

Janet S. Netz

\section{Introduction}

In the past decade, many independent providers of service for high-technology products have sued equipment manufacturers for allegedly excluding them from providing maintenance services. Over twenty antitrust cases have been brought against manufacturers such as Kodak, Prime Computer, Data General, Northern Telecom, Picker, Unisys, Xerox, Rolm, Hewlett-Packard, EDS, General Electric and Siemens. ${ }^{1}$ The common feature in these cases is that the defendants manufacture complex durable equipment for which customers demand service, support, parts, and/or upgrades for many years after the initial sale. The economic interaction between the original equipment market and aftermarkets is central to the analysis.

Most of the cases have a similar plot. The manufacturer sells one brand of complex equipment in a market that is fairly competitive (e.g., the market for minicomputers). In addition, the manufacturer sells aftermarket products to customers who purchased the original equipment. Examples of aftermarket products include hardware maintenance contracts, spare parts, and software upgrades. Due to proprietary rights, the original manufacturer is often the exclusive seller of at least one aftermarket product, such as replacement parts or upgrades to the operating system software. Plaintiffs charge that the manufacturer exploits its aftermarket position in violation of the antitrust laws, typically by tying the purchase of an aftermarket product that is also available from the plaintiffs (usually service) to the manufacturer's proprietary good, that is, by leveraging a monopoly over parts into a monopoly over service.

Once a customer purchases a particular brand of complex, durable equipment, she is likely to be "locked in" to that manufacturer to some extent. There are often significant

1 Each of the authors has advised parties to aftermarket antitrust cases. 
costs of switching to another brand: retraining, sunk investments in custom software, capital losses on the sale of the used equipment, etc. It would seem that these switching costs could provide the manufacturer with room to collect some monopoly rents by raising aftermarket prices above cost. ${ }^{2}$ However, a manufacturer that exploits locked-in customers with high aftermarket prices might make its equipment less attractive when it competes with other manufacturers.

The question we address is fundamental: does substantial competition in the durable equipment market necessarily discipline manufacturers so that they will not exercise market power in the aftermarket? This has been the central claim in the many antitrust cases cited, supported by expert economist testimony from a number of industrial organization economists. ${ }^{3}$ Although there is a recent flurry of articles concerning aftermarket market power, none provide a formal answer to this basic question. ${ }^{4}$ In this paper, we show that equipment competition will not prevent firms from charging supracompetitive prices in their proprietary aftermarkets; the incentive to exercise at least some degree of market power in the aftermarket is unambiguous.

Of course, this is not the only issue in the antitrust cases we have cited and we are not taking a position with regard to any specific allegations of aftermarket monopolization. Shapiro (1995) has wisely noted that the social welfare costs of some aftermarket inefficiencies may be small, and of course there are costs to fashioning a policy remedy. Chen and Ross (1993) have shown that even when the equipment market is monopolized the welfare consequences of some types of aftermarket exploitation are ambiguous. Our objective is to focus attention on the use of aftermarket strategies by durable goods manufacturers. As

\footnotetext{
2 A number of papers demonstrate how the presence of switching costs can endow a firm with market power after consumers make their initial choice. See, e.g., Klemperer (1987) and Farrell and Shapiro (1987). Well-known examples include computers with proprietary operating software and printer toner cartridges for laser and inkjet printers.

3 For example, Kodak argued before the Supreme Court that this proposition must hold as a matter of theory: "even if it concedes monopoly share of the relevant parts market, it cannot actually exercise the necessary market power for a Sherman Act violation .... equipment competition precludes any finding of monopoly power in the derivative aftermarkets'" (Kodak, 112 S. Ct. 2072 (1992) at 2081-82, emphasis in original).

4 See, e.g., Borenstein, MacKie-Mason and Netz (1995), Chen and Ross (1993, 1999), and Shapiro (1995).
} 
a theoretical matter, the assertion that a competitive equipment market prevents a firm from exercising market power in the aftermarket is wrong. As a policy issue, we believe the discussion should focus on the facts of each case and on an assessment of how much harm will occur in each particular situation.

In Section 2 we review the recent legal history, emphasizing how the central economic question has emerged from important fact contexts. In particular, we discuss the role of lock-in and reputational effects. We develop a differentiated Bertrand duopoly model in Section 3 to address the incentive to exercise market power in the aftermarket and its effect on welfare. This model not only approaches perfect competition in the equipment market as the degree of differentiation approaches zero, but it also allows for the existence of some economic profits, which we argue are necessary in order to study how reputation might affect the incentives to exploit aftermarkets. We find that a reputation for low aftermarket prices does have value and that firms will therefore price the aftermarket product below its monopoly level. However, we also find that firms always price above cost for the aftermarket product.

Assertions that equipment market competition will necessarily discipline aftermarket behavior tend to refer to the equipment market as "highly" competitive. Therefore, within the context of our differentiated duopoly, we examine two issues. First, we consider the effects on the aftermarket price as the degree of differentiation between the two firms approaches zero, so that we approach standard Bertrand competition. We continue to find that service price remains higher than $\operatorname{cost}^{5}$ Then, we consider how the option to scrap used equipment and buy new rather than purchase aftermarket service affects the aftermarket price. We show that if the option to scrap and buy new is binding on the margin, the aftermarket price is increasing in the firm's degree of equipment market power. These results emphasize our main point for antitrust analysis: the exercise of aftermarket market power is not ruled out by "highly competitive" equipment markets, but is a matter of degree. Rather than merely assume that aftermarket market power is non-existent or is

5 Alternatively, in the appendix we develop a model of a perfectly competitive equipment market in which each equipment firm monopolizes its service market. We find once again that service price will be above cost. Competition in the equipment market causes firms to make zero profits overall, but a welfare loss occurs due to an aftermarket price above cost. 
significant as a matter of theory, some degree of factual inquiry into the market conditions is appropriate.

We extend the analysis in Section 4 by studying the aftermarket pricing behavior of an equipment monopolist. The fundamental result is the same: we show that the aftermarket price is bounded away from marginal cost, but also is not at the full monopoly aftermarket level. We also show that the monopolist charges less in the aftermarket than does a duopolist, at least in our spatial competition model. We argue that this result has an intuitive explanation: the monopolist can extract a larger share of the surplus created when it lowers the aftermarket price (by raising the equipment price) than can a duopolist, so the monopolist has a stronger incentive to keep the aftermarket price down.

We conclude in section 5 by summarizing our findings and discussing some other incentives to monopolize aftermarkets - some of which may benefit and others of which may harm consumers - that are not modeled here.

\section{Aftermarket Economic Power in the Courts}

There are numerous cases before the federal courts that involve claims of antitrust violations in aftermarkets for service products. Two have recently reached the Supreme Court. In the first, firms selling service for Kodak high-volume photocopiers and micrographic equipment alleged that Kodak adopted a restrictive policy on the availability of spare parts, including tying sales of spare parts to the purchase of other maintenance services from Kodak. The Court upheld the Circuit Court's denial of Kodak's motion for summary judgment, concluding that "it is clearly reasonable to infer that Kodak has market power to raise prices and drive out competition in the aftermarkets ... [and] ... to infer that Kodak chose to gain immediate profits by exerting that market power where locked-in customers, high information costs, and discriminatory pricing limited and perhaps eliminated any long-term loss" (Kodak, 112 S. Ct. 2072 (1992) at 2088). The Kodak case then went to trial; Kodak lost on this issue at trial and on appeal (Image Tech Services v. Eastern Kodak Co., 125 F3d. 1195 (Ninth Circuit, 1997)). In another case, an independent service company alleged that Prime Computer had tied the sale of software support and upgrades to the purchase of hardware maintenance from Prime. Prior to the Supreme Court decision in Kodak, the Sixth Circuit had accepted Prime's argument that competition in the 
equipment market would necessarily discipline aftermarket prices. The Supreme Court overturned this decision shortly after deciding Kodak. The Sixth Circuit then decided that sufficient evidence had been presented to support a finding that it was profitable for Prime to monopolize the service aftermarket (Virtual Maintenance v. Prime Computer, 11 F3d. 660 (Sixth Circuit, 1993)). ${ }^{6}$

Two main features that distinguish aftermarkets have emerged in the many antitrust cases before the courts: the role of customer lock-in in establishing market power and the possibility that reputation effects will prevent manufacturers from profitably exploiting whatever economic power they have in service aftermarkets. We discuss these factors now, before proceeding to our formal model.

\section{Customer Lock-In}

The availability of substitutes limits a manufacturer's ability to charge above-competitive prices for its aftermarket products. An aftermarket customer would choose to sell or scrap the used equipment and purchase anew from a different manufacturer if the original seller raised the service price sufficiently. The extent to which switching costs discourage a customer from changing brands affects how much room the manufacturer has to raise the service price.

The equipment involved in most of the recent antitrust cases is quite sophisticated. The products include minicomputers, hospital CT scanners, telephone PBX switches, highvolume photocopiers and micrographic reproduction equipment. In every case, users and experts have testified to the high costs of switching. ${ }^{7}$ Evidence introduced in the Wang $^{8}$ case showed that typically about eighty percent of minicomputer consumers buy the same brand when they replace their equipment.

\footnotetext{
6 Three recent cases have narrowly interpreted or partially conflicted with the Supreme Court in Kodak. See MacKie-Mason and Metzler (1999) for a discussion of these.

7 For example, a senior design systems manager for Ford Motor Co. testified in Virtual that switching from Prime minicomputers to another brand would shut Ford down. See also Kodak, 112 S.Ct. 2072 (1992) at 2087.

8 Systemcare, Inc. v. Wang Laboratories, D.C. Colo., No. 89-B-1778.
} 
Previous work has demonstrated the role of switching costs in creating market power, but they have focused on a single product to which the customer becomes locked in. ${ }^{9}$ There has been little attention to a firm that sells equipment in a competitive market but sells service to locked-in customers. ${ }^{10}$ When there are two interrelated markets, the central question becomes the ability of the manufacturer to profitably exercise economic power in one market without a larger adverse impact on profits in the other market.

\section{Reputation and Imperfect Competition}

Manufacturers face two types of customers: those who already own equipment and those who are purchasing for the first time. Although customers who already own equipment may face significant costs of switching brands and thus provide the manufacturer with an opportunity to price supracompetitively, de novo customers do not. Do potential new customers provide sufficient competitive discipline in the aftermarket? The answer depends on reputation effects. It may not be profitable for a manufacturer to charge above-competitive aftermarket prices to locked-in service customers if the information easily spreads, inducing potential new consumers to purchase other brands. The direction of this reputation incentive is clear, but its magnitude has not been shown to be great enough to keep aftermarket prices at competitive levels. In particular, it is necessary to study reputation effects taking into account the incentives facing other manufacturers. The pressure from new customers may not be sufficient if the other manufacturers are also charging abovecompetitive aftermarket prices.

The trade-off between earning profits by exercising market power in aftermarkets and losing profits in equipment sales from a reputation for exploiting locked-in service customers has caused some confusion in the courts. The appellate court in Virtual originally argued that "lock-in theory is viable only when the producer can charge its customer monopoly prices without fear of being replaced by competitors due to the customer's substantial investments" (Virtual, 957 F.2d 1318 at 1328). However, it is not necessary to charge the

\footnotetext{
9 See, for example, Farrell and Shapiro (1987), Klemperer (1987), and Beggs and Klemperer (1992).

10 For an exception, see Chen and Ross (1995). In that paper the authors argue that firms charge above-cost service prices to recover higher costs from heavy users during a warranty period.
} 
full monopoly aftermarket price in order to exploit economic power, nor does the loss of some customers for new equipment necessarily offset the profits from service. The Supreme Court observed in Kodak that even monopolists have to give up sales when they raise prices, yet they find it profitable to charge higher than competitive prices (112 S. Ct. 2072 (1992) at 2084), and that short of charging the full monopoly price for service, "there could be a middle, optimum price at which the increased revenues from the higher-priced sales of service and parts would more than compensate for the lower revenues from lost equipment sales" $(i d$.$) . The proper question, then, is the severity of the impact anticompetitive$ behavior in an aftermarket will have on profitability in the equipment market.

The incentive to establish a reputation for low aftermarket prices depends on the manufacturer anticipating the possibility of earning above-normal profits after it has built such a reputation. Thus, there must be some product differentiation or other source of profits or quasi-rents in the equipment market. In fact, vigorous but imperfect competition characterizes many durable equipment markets. Complex, high-technology products tend to be differentiated, even if they are similar enough that customers can consider them as partial substitutes. For example, Wang minicomputers tended to be favored by customers who needed strong document and image processing capabilities; DEC computers by scientific and engineering users; and IBM minicomputers by those with large databases to process. Northern Telecom PBX telephone switches were designed to maintain complete "upward" compatibility so that customers can expand and upgrade their system without replacing it; AT\&T produced different lines of switches that are not all upwardly compatible.

In this section, we have shown that the courts have begun to recognize that durable equipment manufacturers face a tradeoff between above-competitive aftermarket profits from locked-in customers and competitive losses in the equipment market. In the next section, we analyze this tradeoff in a model with imperfectly competitive equipment sellers in section 3 and an equipment monopolist in Section 4. We use these models to study the role of reputation. 


\section{A Model of Competition with Monopolized Aftermarkets}

In this section, we present a simple characteristic-space model of competition between two differentiated products where the markets for the associated aftermarket goods are monopolized by the original equipment manufacturers. The model has the attractive feature that as the "transportation costs" approach zero, the model approaches one of undifferentiated Bertrand competition. It also can be adapted for comparison to a monopoly supplier of both the primary and aftermarket good, as we show in the following section. Using this model, we show that competitive firms will always have an incentive to price their (monopoly) aftermarket sales above competitive levels, even as the degree of differentiation between the firms becomes arbitrarily small and the foremarket becomes arbitrarily close to undifferentiated Bertrand competition. We demonstrate that no equilibrium can exist in which the price of the aftermarket product always is set equal to marginal cost.

\section{Model Assumptions}

Consider the markets for a durable good - which we call "equipment" - and an associated aftermarket product, which we call "service." We suppose there are two firms, a and $b$, from whom the customer may purchase new equipment, but that each equipment manufacturer is the only seller of service associated with its brand. ${ }^{11}$ Thus, after buying and using equipment in period $t$, in period $t+1$ the consumer can (1) use the product in its depreciated state with no addition of service, (2) buy some quantity of service from the same manufacturer to enhance the equipment, or (3) scrap the used equipment and purchase new equipment again, from either manufacturer. ${ }^{12}$

The equipment and service products each have constant unit production costs, $C$ and $c$ respectively, identical for all firms. We assume that consumers are locked-in to their equipment manufacturer if they want to purchase service: an owner of firm $a$ 's equipment

11 For now we suppress subscripts denoting different equipment brands, because the modeling assumptions hold for each brand. We introduce brand subscripts below when we begin to analyze consumer choice between brands.

12 We assume enough homogeneity across consumers that there will be no polymorphous equilibrium with some consumers buying used equipment from others who then buy new. Allowing for enough heterogeneity to support trade in used goods does not change our main result. 
cannot buy service from firm $b$. However, we do not need to assume lock-in costs for subsequent equipment purchases, and thus for simplicity do not introduce equipment brand switching costs. ${ }^{13}$ That is, a consumer can buy any brand from any vendor with no penalty, regardless of which brand she may have purchased in the past. We further assume that there is no asymmetric information between buyers and sellers.

The firms are located at opposite ends of a unit-length characteristic-space line. Consumers' most preferred points in the space are distributed uniformly along the line, with the total number of consumers normalized to one. Each consumer has a reservation value, $s$, for the "ideal" good located at the consumer's most preferred point in characteristic space. This value is high enough that each consumer buys one unit of the good from the dealer that offers the highest expected discounted consumer surplus. All consumers have equal "travel" costs, $\tau$ per unit distance, that reflect the loss in consumer surplus from having to consume a good that differs from the consumer's most preferred characteristic. Since this cost is associated with persistent product differentiation it is incurred in every period, whether the consumer uses new or old equipment.

Thus, a consumer located at distance $d$ from firm $a$ receives gross surplus from owning the equipment: $C S^{1}=s-\tau d$ from using a new product and $C S^{2}=s-\tau d-h+f(q)$ from using a period-old product that has been augmented with $q$ units of service, where $h$ represents the depreciation in the value of the product from one period of use. The function $f(\cdot)$ is the consumer surplus from $q$ units of service, and is simply the integral of the inverse demand for service, with $f(0)=0, f^{\prime}(\cdot)>0$, and $f^{\prime \prime}(\cdot)<0$.

To make the analysis informative, we assume for each brand that (1) $s-\tau d-h+$ $f(q(c))-c q(c)>s-\tau d-C$ for some $q \geq 0$ and $(2) f^{\prime}(0)>c$. The first assumption ensures that re-using the period-old product would be preferred to buying a new unit of the same brand each period if both new equipment and service were priced at cost. The second assumption assures that purchase of at least a small quantity of service would give positive net consumer surplus if it were priced at cost. Together, the two assumptions

13 Adding brand switching costs would strengthen our results; that is, with brand switching costs aftermarket prices would deviate even farther from marginal cost. 
imply that in a first-best solution consumers use a unit of equipment for two periods and purchase some positive quantity of service in the second period.

We need to specify the flow of consumers into the market over time. For now, we assume that there are two equal-sized consumer cohorts who first want to purchase new equipment in successive periods. If consumers use equipment for two periods, then they reappear as customers for new equipment in the third period and we have a stationary overlapping generations model. ${ }^{14}$ We assume consumers live forever and have an infinite decision horizon subject to discounting with a factor $\delta$ per period. We will return to the issue of market growth or decline below.

The fundamental assumption of our analysis is that firms cannot credibly commit to future service prices. Therefore, to complete the model we must specify consumer beliefs about future service prices, since they are purchasing equipment with a useful life of two periods, and the value of new equipment today will depend on expected service price tomorrow. We take a simple approach to beliefs: consumers' take the firm's service price in period $t$ to be the best indicator of the price the firm will charge in period $t+1$.

There are several points that support our use of this simple assumption. First, costs and the number of consumers are constant over time in our model and the horizon is infinite, so there are no exogenous drivers that would tend to make prices change over time. Second, this model of consumer beliefs corresponds closely to actual behavior suggested by the evidence of many aftermarket antitrust cases. ${ }^{15}$ Third, and most importantly, our goal is to examine the claim that the service price will always be set at the competitive level. Since costs do not change over time in the model, consumers' expectations of constant prices over time would be fulfilled if this claim holds true.

For now we suppose that in equilibrium the price of service is sufficiently low relative to the price of new equipment from each firm that consumers will always prefer to keep and

14 Alternatively, one could view this as new equal-sized cohorts appearing every period and living for two periods.

15 Testimony in many of the legal cases cited in the previous section indicates that consumers who consider service costs at all in choosing among brands make roughly this assumption. We are aware of no cases in which attempts to calculate "lifetime" costs of equipment have included forecasts of future changes in service prices beyond simple extrapolation or inflation adjustment. 
service used equipment after one period, rather than scrap it and buy new each period. We return to this assumption below in order to study the constraining effect that the option to scrap used and buy new has on service pricing.

We summarize the model before we undertake the analysis:

- A steady number of new customers arrive to purchase equipment from one of two firms in any period.

- Equipment is sufficiently durable that consumers choose to keep it for two periods, while purchasing service to enhance its second period value.

- Consumers expect future service prices to be the same as current prices.

- Firms are monopolists over service for their own brand of equipment, but set the service price knowing that current service prices affect current consumer willingness to pay for new equipment.

- Equipment prices are set under conditions of differentiated product duopoly competition, with a uniform distribution of consumer types along a characteristics line separating the two equipment brands.

\section{Analysis of the Duopoly Model}

We have specified a rather general infinite-horizon overlapping generations duopoly game. Our goal is not to find all equilibria of this game, however. We are motivated by the fundamental question repeatedly raised in antitrust lawsuits and the ensuing academic discussion: will competition in the equipment market sufficiently discipline aftermarket service pricing so that there is no exercise of monopoly power in the aftermarket? We interpret an exercise of aftermarket market power to imply that $p^{t}>c$ for at least some periods $t$, where $p$ is the aftermarket price. Therefore, we ask the following question: is there an equilibrium in the market described in which firms choose a constant service price equal to marginal cost in every period: $p^{t}=c, \quad \forall t ?$

Our approach is to use the necessary conditions for a constant price equilibrium to show that if such an equilibrium exists, $p^{t}=\bar{p}>c$, i.e., service price will always be above cost. That is sufficient to answer the main question, since if a non-constant price equilibrium 
exists, it is straightforward to show that it must have $p^{t}>c$ in at least some periods $t .{ }^{16}$ After we show that in a constant price equilibrium, if one exists, service price is above cost, we will establish that Marshallian welfare is less than it would be if marginal cost service pricing prevailed in all periods, thus establishing that this exercise of market power has adverse welfare consequences.

After establishing the main result, we further interpret the necessary conditions to characterize the effects of the discount rate or market growth rate on service pricing. We then examine how variations in the degree of equipment competition - from undifferentiated Bertrand competition to monopoly markets - affect the result that service is priced above cost. Finally, we consider the effect that competition from new equipment has on service prices, and with this generalized model we can also examine how the degree of equipment durability affects service pricing.

Consider the consumer surplus from equipment purchased in the current period and service on that equipment in the next period. If a consumer located at distance $d$ from firm $a$ assumes that she will face the same price for service next period as a offers currently, $p_{a}$, she gets expected net consumer surplus from brand $a$ of

$$
C S_{a}=\left[s-\tau d-P_{a}\right]+\delta\left[s-\tau d-h+f\left(q\left(p_{a}\right)\right)-p_{a} q\left(p_{a}\right)\right]
$$

where capital $P$ refers to equipment and small $p$ and $q$ refer to the service product. The consumer is distance $(1-d)$ from firm $b$, so her expected consumer surplus from firm $b$ is given by

$$
C S_{b}=\left[s-\tau(1-d)-P_{b}\right]+\delta\left[s-\tau(1-d)-h+f\left(q\left(p_{b}\right)\right)-p_{b} q\left(p_{b}\right)\right]
$$

The consumer who is indifferent between buying from firm $a$ and from firm $b$ marks the boundary between the two firms' markets. Setting the consumer surpluses equal and solving for $d$ yields the market boundary, denoted $\hat{d}$ :

$$
\hat{d}=\frac{\tau(1+\delta)+\left(P_{b}-P_{a}\right)+\delta \phi}{2 \tau(1+\delta)},
$$

\footnotetext{
16 After we prove our main result, it is easy to show that no equilibrium exists in which $p^{t}=c$ for some $t$ and $p^{\hat{t}}<c$ for all other $\hat{t} \neq t$.
} 
where $\phi$, a function of $p_{a}$ and $p_{b}$, is the difference in the net surplus of each brand, $a$ and $b$, that the consumer would receive in the second period after buying service: ${ }^{17}$

$$
\phi \equiv c s\left(p_{a}\right)-c s\left(p_{b}\right) \equiv\left[f\left(q\left(p_{a}\right)\right)-p_{a} q\left(p_{a}\right)\right]-\left[f\left(q\left(p_{b}\right)\right)-p_{b} q\left(p_{b}\right)\right]
$$

We assume that production costs of both the equipment and service products are linear in quantity; without further loss of generality, we take these costs to be zero, so that firm a's equipment and service profit on one generation of equipment sales is given by

$$
\Pi_{a}=P_{a} \hat{d}+\delta p_{a} q\left(p_{a}\right) \hat{d}=\hat{d}\left[P_{a}+\delta \pi_{a}\right]
$$

where $\pi_{a}=p_{a} q\left(p_{a}\right)$, the profit per unit of equipment from sales of service, and similarly for firm $b$.

We now proceed to characterize the profit-maximizing equipment and service prices for each firm through analysis of necessary conditions for an equilibrium. To do this, we derive the infinite horizon value function for each firm at a given moment in time, assuming an arbitrary initial market share, $d^{0}$.

Recall that we restrict our analysis to constant pricing strategies, so the choice variables are $P^{t}=P$ and $p^{t}=p, \forall t$, for each firm. If firm $a$ expects to face a steady stream of customers choosing between brands for new equipment in each period, then it will earn profits from each customer generation of $\hat{d}\left[P_{a}+\delta \pi_{a}\right]$. If the firm expects stationary equilibrium behavior from its competitor, ${ }^{18}$ then, given a current market share of $d^{0}$ for customers already locked in, the present value of its stream of profits forevermore will be

$$
V_{a}=d^{0} \pi_{a}\left(p_{a}\right)+\hat{d}\left(P_{a}, P_{b}, p_{a}, p_{b}\right)\left[P_{a}+\delta \pi_{a}\left(p_{a}\right)\right]\left[1+\frac{\delta}{1-\delta}\right] .
$$

A strategy choice is a simultaneous announcement of $(P, p)$, so necessary conditions for an optimal strategy can be found from the stationary points of $V$ with respect to $(P, p)$.

17 To guarantee that the duopolists cover the entire market, we also assume that the gross surplus from service-augmented equipment is sufficiently large compared to the travel cost: $s+\delta\left[s-h+f\left(q\left(p_{a}\right)\right)\right]>$ $1.5 \tau(1+\delta)$. If the inequality does not hold, then the duopolists will earn higher profits by pricing in such a way that the markets of the two do not overlap; that is, each duopolist chooses to be a local monopolist.

18 If a constant price equilibrium exists, then these expectations will be fulfilled when that equilibrium is realized. 
Substituting for $\hat{d}$ from (3) and setting the derivative of (5) with respect to $P_{a}$ equal to zero, we obtain firm $a$ 's best response function:

$$
P_{a}=\frac{\tau(1+\delta)+P_{b}+\delta\left(\phi-\pi_{a}\right)}{2} .
$$

Doing likewise for $P_{b}$, and then solving the two equations simultaneously, yields two necessary conditions for equilibrium equipment prices that are solely a function of service prices and exogenous factors:

$$
P_{a}=\tau(1+\delta)+\frac{\delta}{3}\left[\phi\left(p_{a}, p_{b}\right)-\pi_{b}\left(p_{b}\right)-2 \pi_{a}\left(p_{a}\right)\right]
$$

and

$$
P_{b}=\tau(1+\delta)+\frac{\delta}{3}\left[-\phi\left(p_{a}, p_{b}\right)-\pi_{a}\left(p_{a}\right)-2 \pi_{b}\left(p_{b}\right)\right] .
$$

We can substitute these expressions into $V_{a}$ and take the derivative with respect to the service price, $p_{a}$, to obtain

$$
\frac{\partial V_{a}}{\partial p_{a}}=d^{0} \pi_{a}^{\prime}+\frac{\delta}{1-\delta}\left[\frac{1}{2}+\frac{\delta\left(\phi+\pi_{a}-\pi_{b}\right)}{6 \tau(1+\delta)}\right] \frac{2\left(\phi^{\prime}+\pi_{a}^{\prime}\right)}{3},
$$

where primes indicate derivatives with respect to $p_{a}$. The first term is the change in current period profits on service from raising $p_{a}$. The second term has three components, the first of which is the present value factor for the infinite horizon stream of profits. The second part is equal to the firm's equilibrium market share or quantity sold of equipment, $\hat{d}$, after substituting in the solutions for optimal equipment prices $P_{a}$ and $P_{b}$. The third part is proportional to the difference between the loss in consumer surplus and the gain in profits from an increase in the price for service $p_{a}$. The difference is the marginal deadweight loss from raising the price of service.

To evaluate this expression, note that at $p_{a}=0$ (marginal cost), total surplus is maximized, and thus marginal surplus $\phi^{\prime}+\pi_{a}^{\prime}=0$. That is, to a first order, a slight increase in the price of service from marginal cost raises service profits by the same amount that it lowers consumer surplus. Then,

$$
\left.\frac{\partial V_{a}}{\partial p_{a}}\right|_{p_{a}=0}=d^{0} \pi_{a}^{\prime}>0
$$

and a profit-maximizing firm with an installed base will always set the price of the service product above marginal cost.

We have now proven our main result: 
Result 1. No equilibrium exists in which the firms charge a service price equal to marginal cost in every period. If a constant price equilibrium does exist, the firms charge a service price above marginal cost.

This result is quite general, not an artifact of the specific model. If the price of service is equal to its marginal cost, a small increase in that price will have only a second order effect on future profits once the price of the equipment is optimally adjusted downward, because this creates only second order deadweight loss, but it will have a first-order effect on current period profits from selling the service product, because the associated equipment units already have been sold. For this reason, it will always be profitable for the firm to raise the price of service above marginal cost.

In fact, this result relies on none of the attributes of the spatial model beyond the value function, (5). Equation (5) makes it clear that there are two fundamental forces at work in the firm's optimization problem at any point in time. The second term on the right-hand side of (5) is the present value of profits the firm could earn in aggregate from every generation of buyers except those who have already purchased from it. Given the consumer beliefs we have posited, the firm could charge a price equal to marginal cost for service starting today, and in that way could exactly maximize the profit it earns on all future generations of buyers (recall at $p=c$ we have $\phi^{\prime}+\pi_{a}^{\prime}=0$ ). If that were the entire calculation, the firm would simply price service at its marginal cost. But at any point in time, the firm will also have the first term on the right-hand side of (5). This term represents the profit it can earn on the consumers who have already purchased their equipment. This term is maximized by charging the monopoly price for service. As we show in the next subsection, the firm would like to charge the monopoly service price to these "locked-in" customers while still assuring future customers that it will charge a lower price (equal to marginal cost) when they return to buy service. This is exactly what the firm would do if it could make a binding commitment to future prices, but we are interested in the typical case in which long-term complete contracts are not feasible. 


\section{Locked-in Customers and Commitment}

Since the result relies crucially on the installed base of customers who already own equipment, $d^{0}$, one might wonder if our conclusion fails when there is no installed base (or for a new entrant in a model that permits entry). Our result is robust to this concern. We have examined the necessary conditions for an equilibrium in which the firms choose to restrict themselves to constant pricing over time. It is easy to show, however, that at $t=0$, with no installed base customers, a constant price strategy with $p=c$ cannot be optimal in the wider strategy space that includes the possibility of nonconstant pricing over time. To see this, suppose that the firm did announce $p=c$ in the first period. In the second period it would have some installed base $d^{0}\left(P_{a}^{0}, P_{b}^{0}, p_{a}^{0}, p_{b}^{0}\right)$. At this point, it would pay to deviate from $p=c$ by reverting to the strategy we analyzed above, with $p>c$. The main claim holds: if the firm cannot pre-commit to service prices over the lifetime of equipment, it will not be profitable to follow a strategy of constant service prices equal to cost.

Further examination of the first order condition, (9), also leads to the conclusion that the firm will not choose to charge the static monopoly price for service, where $\pi_{a}^{\prime}=0$, either. At that point, the first term in (9) would be zero. The second term, however, would be negative, ${ }^{19}$ so the derivative of the value function with respect to $p_{a}$ would be negative. Thus, if a constant price equilibrium exists it will occur with a price of service that is strictly greater than marginal cost, but strictly less than the static monopoly price. ${ }^{20}$

Would the firms prefer to commit to marginal cost pricing if they could? Suppose a commitment "technology" (e.g., feasible long-term complete contracts) were introduced at some date when the two firms already have some locked-in customers. We show that in this case it would be an equilibrium for both firms to charge the full monopoly service

19 The component $\frac{\delta}{(1-\delta)}$ is positive for the relevant range of $\delta \in(0,1)$ The second component is positive so long as firm $a$ has positive market share. The component $\left(\phi^{\prime}+\pi_{a}^{\prime}\right)$ is negative for $p_{a}>0$, because price increases above marginal cost decrease consumer surplus by more than they increase profits, thus creating increased deadweight loss. Hence, the product of these three components will be negative.

20 The two results on the first-order condition for the value function at $p_{a}=0(m c)$ and $p_{a}=p_{m}$ are sufficient to guarantee that there is at least one local maximum for $m c<p_{a}<p_{m}$. 
price to current locked-in service customers, but to commit to charge a service price equal to marginal cost thereafter.

First, reconsider firm a's necessary condition for optimal service pricing in (9). With a commitment technology, firm a can now charge a different price to current locked-in service customers and future equipment purchasers, so the two terms in (9) are de-coupled and the firm optimizes by setting them separately to zero. This occurs when the current service price is the monopoly price $\left(\pi_{a}^{\prime}=0\right)$, and the future service price is set to marginal cost (so that total marginal surplus $\phi^{\prime}+\pi_{a}^{\prime}=0$ ). The symmetric analysis holds for firm $b$.

From (7) and (8), both firms then charge an equipment price $P_{a}=P_{b}=\tau(1+\delta)$. With equal service and equipment prices they split the market, $\hat{d}=\frac{1}{2}$ (from (3)), and each firm earns profits $\Pi=\frac{1}{2} \tau(1+\delta)$ on each two-period generation of equipment sales (from (4)). By comparison, without commitment (7) and (9) lead firm $a$ to charge $P_{a}=\tau(1+\delta)-\delta \pi_{a}$, and two-period generational profits would still be $\Pi=\frac{1}{2} \tau(1+\delta)$ (from (4)). Thus, if both firms did commit, the profits on all future generations of equipment sales would be the same as in the no-commitment case. However, they would be able to charge the monopoly service price on current locked-in customers, and, as we showed above, the no-commitment price is less than the monopoly price. Thus, both firms are better off with commitment than without.

When commitment is possible, it is an equilibrium for both firms to commit to charging $p=m c$ in the aftermarket in all future periods. To see this, suppose firm $a$ deviates to a non-commitment strategy. The future service price will be set above marginal cost, and the current service price will be set equal to the future price (by assumption), below the monopoly price as shown above. Obviously, profits on current locked-in customers will fall. In addition, when $p_{a}$ increases for future customers, $\phi+\pi_{a}=f\left(q\left(p_{a}\right)\right)-\left[f\left(q\left(p_{b}\right)\right)-p_{b} q\left(p_{b}\right)\right]$ decreases because consumer surplus decreases, and thus per customer generational profits on new equipment sales fall. The same calculation on $\pi_{a}+\phi$ implies that $P_{a}-\delta \phi$ increases, and thus firm a's market share, not surprisingly, will fall, so it earns smaller generational profits on fewer customers. Thus, each term in the value function (5) decreases, and firm $a$ does not wish to deviate from committing to future marginal cost pricing of service. The symmetric analysis holds for firm $b$, and simultaneous commitment is a Nash equilibrium. 
Consumers also benefit from the introduction of a commitment technology. As the price of the aftermarket product rises, consumers lose on the inframarginal and marginal units of service. Because the duopolists compete for the consumers in the equipment market, the loss to consumers on the inframarginal units is recovered via a lower equipment price. The consumers do not, however, recover the loss of net consumer surplus on the marginal units. Thus marginal cost service pricing is a Pareto improvement. ${ }^{21}$

It might appear that in our analysis effectively we have allowed the firm to commit to future prices, since consumers assume that tomorrow's price is the same as today's. However, this merely implies that if the firm follows a constant price strategy, consumer beliefs will be fulfilled. There is nothing about the beliefs assumption that stops the firm from raising price. It is true that for our proof of Result 1 we assumed the firms follow constant price strategies. We did not, however, allow the firm to make an enforceable commitment to charge a constant price (equal to marginal cost). Thus, it is not possible in our model for the firm to charge the monopoly price to current locked-in customers and marginal cost to all future customers, which is what it would do if commitment were possible.

\section{The Effect of the Discount Rate and Market Growth}

From (9) we can see the effect of the discount rate:

Result 2. If a constant price equilibrium exists, the exercise of market power in the service market will be greater the higher is the discount rate.

As $\delta$ goes to zero, so that future profits receive a decreasing weight, service is priced closer to the static monopoly level $\left(\pi_{a}^{\prime} \rightarrow 0\right)$. As $\delta$ goes to one, so that future profits receive an increasing weight, service is priced closer to marginal cost (using L'Hôpital's rule, the first order condition requires $\phi^{\prime}+\pi_{a}^{\prime} \rightarrow 0$, which implies $\left.p_{a} \rightarrow 0\right)$. Although $\delta$ is the discount

21 Similar reasoning allows us to rule out an equilibrium in which $p^{t}=c$ for some $t$ and $p^{\hat{t}}<c$ for all other $\hat{t} \neq t$. A price below marginal cost for service raises (expected) consumer surplus by less than it lowers producer profits, so even ignoring the incentive to exploit locked-in consumers with a high service price, a producer could increase its profits and consumers' expected surplus at the time they buy the equipment by raising its service price to be always equal to marginal cost and lowering its equipment price commensurately. 
factor, it can be interpreted as measuring change in the expected size of the market. If the market is growing over time, then a higher market share for future equipment sales is of greater value, assuming that new customers in the market learn of aftermarket pricing reputations. The greater weight on future sales can be expressed as an increase in $\delta .^{22}$ If the market is declining in size, then future market share is less valuable, implying a lower $\delta$ and an increase in the price of service towards the monopoly level.

\section{The Effect of Increasing Competition}

The antitrust cases that in part motivated this inquiry generally assume that the market for equipment is "highly competitive." It is not always clear just what is meant, but in many cases there is little disagreement that the equipment market is competitive. Therefore, we would like to answer the question of whether a perfectly competitive equipment market sufficiently disciplines the service market that the aftermarket price will be equal to marginal cost.

In the appendix we present a finite horizon model with a perfectly competitive equipment market. Our main result holds: there is not an equilibrium in which service prices are always equal to marginal cost. In fact, we can show the stronger result that in equilibrium service prices are always above marginal cost; indeed, in some parts of the parameter space the service price is set at the monopoly level. However, when we try to solve an infinite horizon model comparable to model in this section, an equilibrium does not exist. ${ }^{23}$ The problem is simple, but fundamental: with free entry in the equipment market, there are no intrinsic rents to equipment manufacturing. With zero profits, there is no incentive to build and maintain a reputation for low service prices. Instead, with the static expectations that we assume for consumers, firms lower service prices to build market share,

22 Strictly speaking, this interpretation only holds precisely if the market growth rate is such that it can be represented by a once and for all increase in $\delta$, so that $\delta$ is at a higher level but still constant over time. If $\delta$ changes for a firm, however, we would expect firms to change their aftermarket pricing - e.g., raising aftermarket prices as it becomes apparent that a product is likely to exit the market earlier than had previously been expected. In such cases, the consumers' static expectations would not be fulfilled over the periods in which $\delta$ changes.

23 Analogous existence problems arise in the quality reputation literature. See, e.g., Klein and Leffler (1981). 
and then revert to high prices to exploit their customer base. This dynamic prevents the existence of an equilibrium. However, we can show that the main result continues to holds by demonstrating that setting service prices equal to marginal cost in every period is not an equilibrium.

In this section we take a different approach to showing the effect that increasing equipment competition has on the pricing of aftermarket service. As we let the "transport" cost, $\tau$, go to zero, the degree of product differentiation in our duopoly model goes to zero. In the limit, we have an undifferentiated Bertrand duopoly game, and the usual outcome obtains: industry profits are competed to zero. Even with undifferentiated product Bertrand competition, service is still priced above cost, and our main result holds: equipment market competition does not induce competitive aftermarket pricing.

To see the result, examine the necessary conditions for a constant-pricing equilibrium, (9). As $\tau \rightarrow 0$, the second term in square brackets has a denominator that goes to zero. In order to satisfy this first order condition, then, the service price must be chosen so that the numerator also goes to zero. That is, as $\tau \rightarrow 0$ then $\phi+\pi_{a}-\pi_{b} \rightarrow 0$. Using this fact and taking the limit of the equipment market price in (7) as $\tau \rightarrow 0$, we get $P_{a} \rightarrow-\delta \pi_{a}$, which is to say that two period profits in equation (4) go to zero. By applying L'Hôpital's rule to expression (3) for the market share boundary, $\hat{d}$, we see that the market is evenly split $\left(\hat{d}=\frac{1}{2}\right)$. Thus, as product differentiation goes to zero, we get the standard Bertrand duopoly result (with symmetric costs) that industry profits are competed to zero and the market is equally divided.

If we now evaluate the limit of the necessary condition (9) with service price equal to cost, $p_{a}=0$, as we did before, we see that the same result holds: if there is a constant price equilibrium, it must be that service price in that equilibrium is above cost because the derivative of the value function with respect to price is positive when evaluated at marginal cost, as in expression (10).

This result for undifferentiated Bertrand duopoly shares another feature with our finite horizon perfect competition model (in the appendix): we can show that equipment is priced below its marginal cost. Service prices are above cost, and thus service profits are positive. However, we have shown above that two-period profits from the sale of equipment 
and service are zero. Thus, equipment profits are negative, or $P<C$; undifferentiated Bertrand competitors lower equipment prices to compete away all of the anticipated service profits.

As in the differentiated duopoly case, the ability to commit to efficient service prices yields a Pareto improvement. Although firm profits remain at zero and thus are not improved, consumers are made better off. The intuition for the formal argument is the following: all consumers buy equipment in either case, so first-period social welfare is unchanged. The reduction in second-period service price reduces deadweight loss from the choice of how much service to purchase, so second-period - and overall - welfare is increased. Firm profits are zero in both cases, so consumers must be better off.

More generally, we can evaluate the role of competition by looking at the conditions for a steady state in this model. Equation (9) and the equivalent condition for $p_{b}$ implicitly define best-response functions that together determine an equilibrium at any point in time. In steady state, however, a third condition must hold, $d^{0}=\hat{d}$. In this case, the static expectations about service prices that we have assumed for consumers are fulfilled. Imposing this condition on (9) and again substituting for $\hat{d}$ from (3), (7), and (8), then factoring out the $\hat{d}$ expression gives the steady state conditions

$$
\frac{\partial V_{a}}{\partial p_{a}}=\left[\frac{1}{2}+\frac{\delta\left(\phi+\pi_{a}-\pi_{b}\right)}{6 \tau(1+\delta)}\right] \cdot\left[\pi_{a}^{\prime}+\frac{\delta}{1-\delta} \cdot \frac{2\left(\phi^{\prime}+\pi_{a}^{\prime}\right)}{3}\right]=0
$$

and the equivalent expression for $p_{b}$. The first term is the equilibrium market share, so for the equilibrium to exist at an interior solution, the second term must be equal to zero. We can see from this that the degree to which the price of service exceeds the cost of providing service depends only on the shape of the demand curve for service and the degree to which the firm discounts future profits. Notably, $\tau$ does not appear in the second term. The extent of substitutability among brands in the equipment market, which determines the severity of competition, does not affect the equilibrium price of the aftermarket product in this model. ${ }^{24}$

24 This result is conditional on our current assumption that new equipment is not an economically viable alternative to servicing used equipment. We relax this assumption below. 
This surprising result depends on the assumption that a consumer's strength of preference between brands, $\tau$, and location on the line is uncorrelated with her demand for the aftermarket product. When this is true, the service price is not a useful policy instrument for maximizing profits as the level of competition changes. The firm sets service price to optimally balance the reputation and lock-in market power incentives. It responds to changes in competition only by adjusting its equipment price. In some situations, however, $\tau$ may not be independent of the demand for service or the importance of reputation. In those cases, the changes in $\tau$ can influence the aftermarket price, as we discuss in Section 5 . More importantly, this result will not necessarily hold if consumers consider abandonment of the equipment after one period a realistic alternative, as we discuss below.

While equation (11) and the equivalent expression for $p_{b}$ together characterize the steady state in this market, we have not studied the dynamic path to the steady state. Away from the steady state, the optimum conditions for service prices will not be exactly as shown in (11), because there will be a dynamic consideration: a given share of equipment sales this period will affect the optimal service price next period, which will help determine the share of equipment sales next period and thus the optimal service price in two periods, etc. In that process, it appears that $\tau$ might affect the degree of above-cost pricing of the aftermarket product. Nonetheless, competition will still fail to drive the aftermarket price to marginal cost.

\section{Competition Between Service and New Equipment}

We have thus far analyzed the model without recognizing the possibility that consumers might abandon equipment after one period and purchase new equipment rather than servicing the used equipment. Given the structure of the model - in which consumers are homogeneous except for their location on the line and must pay the transportation cost each period regardless of whether they service used equipment or buy new - it is clear that there will be a threshold price of service relative to equipment that would induce all of the customers of a firm to abandon their used equipment. This would never be efficient under the assumptions of the model, and a firm would always be better off setting price just below this threshold than inducing equipment abandonment. 
Thus, there are two types of equilibria that could occur depending on whether or not the equipment abandonment constraint is binding. To assure that the consumer services equipment in the second period rather than abandoning it and buying new, the necessary condition is that $s-\tau d-P_{a}<s-\tau d-h+f\left(q\left(p_{a}\right)\right)-p_{a} q\left(p_{a}\right)$, or $P_{a}>h-f\left(q\left(p_{a}\right)\right)+p_{a} q\left(p_{a}\right)$. This constraint is more likely to bind if equipment is inexpensive $\left(P_{a}\right.$ small $)$ relative to the loss in value from using a second-period piece of equipment after optimal servicing $\left(h-f\left(q\left(p_{a}\right)\right)+p_{a} q\left(p_{a}\right)\right)$. If equipment is very expensive and used equipment has high value relative to new, then this constraint won't bind and the discussion above will correctly characterize the market.

If the constraint does bind, then new equipment competes with servicing used equipment, which changes the effects of competition among sellers. Given symmetry between firms, $\phi=0$ and $\pi_{a}=\pi_{b}$. Plugging these conditions into the equilibrium equipment price (7), we have $P_{a}=\tau(1+\delta)-(\delta / 3) \pi_{a}$. Then the equipment servicing condition can be re-written as: $f\left(q\left(p_{a}\right)\right)-p_{a} q\left(p_{a}\right)>h-\tau(1+\delta)+(\delta / 3) \pi_{a}$. What is noteworthy about this result is that $\tau$, the degree of competition between the firms, now matters: as competition increases $(\tau$ falls), the consumer must be left with more consumer surplus from service to prevent her from abandoning her used equipment. More competition in the equipment market lowers the price in the service market. Nonetheless, so long as it is efficient to service used equipment - i.e., consumers strictly prefer servicing used equipment to buying new each period when both equipment and service are priced at marginal cost - the threat of equipment abandonment can never drive the price of service to its marginal cost, so the firm will still never maximize profits by setting the price of service equal to marginal cost.

One interesting result that follows from this discussion is that we can characterize the effect that durability has on the exercise of aftermarket power. We can interpret $C-h$ as a measure of "durability". As the equipment production cost, $C$, increases relative to the quality loss as equipment ages, $h$, the option to discard one-period-old equipment becomes less attractive (the opportunity cost of early disposal is greater). Although it is obscured above by our assumption that $C=0$, we can replace $h$ with $h-C$ in the above inequalities, and see that when the new equipment constraint is binding, an increase in durability (lower $h-C$ ) makes the constraint less binding, so the firm can charge a 
higher service price without inducing consumers to scrap used equipment and buy new. Therefore, when new equipment poses a binding constraint on aftermarket pricing, greater durability is associated with higher aftermarket prices.

\section{A Monopoly in the Equipment Market}

To complete the analysis, we consider the case of monopoly in the equipment market. For the purpose of comparison, we continue to use a linear spatial model. We assume that the monopolist is located at the endpoint of the characteristic-space in order to make the set-up most similar to the duopoly setting. ${ }^{25}$

A consumer buys equipment, holds it for two periods, and services it the second period if her total net consumer surplus is non-negative; that is if

$$
s-\tau d-P_{m}+\delta\left[s-\tau d-h+f\left(q\left(p_{m}\right)\right)-p_{m} q\left(p_{m}\right)\right] \geq 0
$$

For now we assume that the consumer receives sufficient surplus from servicing period-old equipment that she does not buy new; we will return to this assumption later.

The market boundary of the monopolist, $\hat{d}_{m}$, is determined by the consumer who receives zero surplus:

$$
\hat{d}_{m}=\frac{1}{\tau(1+\delta)}\left[s-P_{m}+\delta\left[s-h+f\left(q\left(p_{m}\right)\right)-\pi\left(p_{m}\right)\right]\right]
$$

where $\pi\left(p_{m}\right)=p_{m} q\left(p_{m}\right)$, since we continue to assume that production costs are zero. ${ }^{26}$

Consider the value function for a monopolist with initial sales of $d_{m}^{0}$. We assume that the monopolist's market share will be the same in every subsequent period, and, as before,

25 An alternative interpretation is for $\tau$ to be sufficiently large that the marginal customer for either firm is outside the market of the other firm; there is a gap in the middle of the market where consumers do not buy either product, so each firm is a local monopolist.

26 Depending on gross consumer surplus relative to the transportation cost, the monopolist may or may not serve the entire market. If transport costs are high relative to gross surplus, the monopolist maximizes profits by not serving the entire market; in particular, some consumers opt out of the market if $s+\delta\left[s-h+f\left(q\left(p_{m}\right)\right)\right]<2 \tau(1+\delta)$. If the inequality does not hold, then the monopolist serves the entire market and $\hat{d}_{m}=1$. We assume that the inequality does hold to most closely parallel the duopoly situation. The result is that the monopolist faces a linear demand curve with vertical intercept $s$ and slope $-\tau$. In this case, both a monopolist and a duopolist face a trade-off in setting the price of service: as price rises above cost, profits on locked-in customers rise but profits on future generations of customers fall because the market share of the firm falls. 
we restrict ourselves to situations in which the firm chooses to charge the same service price in every period:

$$
V_{m}=d_{m}^{0} \pi\left(p_{m}\right)+\hat{d}_{m}\left[P_{m}+\delta \pi\left(p_{m}\right)\right] \frac{1}{1-\delta}
$$

Substituting for $\hat{d}_{m}$ from (13) and taking the derivative with respect to the equipment price yields the first-order condition for the equipment price. Solving for the optimal equipment price as a function of the service price gives:

$$
P_{m}=\frac{1}{2}\left(s+\delta\left[s-h+f\left(q\left(p_{m}\right)\right)-2 \pi\left(p_{m}\right)\right]\right) .
$$

Substituting this expression and (13) in (14) yields profit as a function of service price only:

$$
V_{m}=d_{m}^{0} \pi\left(p_{m}\right)+\frac{1}{4 \tau(1+\delta)} \frac{1}{1-\delta}\left(s+\delta\left[s-h+f\left(q\left(p_{m}\right)\right)\right]\right)^{2} .
$$

Now we can calculate the first order condition for optimal service pricing. After rearranging and evaluating at the steady state, i.e., $d_{m}^{0}=\hat{d}_{m}$, we have:

$$
\frac{\partial V_{m}}{\partial p_{m}}=\hat{d}_{m}\left(p_{m}\right)\left[\pi^{\prime}\left(p_{m}\right)+\frac{\delta}{1-\delta} f^{\prime}(q) q^{\prime}\left(p_{m}\right)\right]=0 .
$$

At $p=c$, total surplus in the service market is maximized, so marginal surplus, which is $f^{\prime}(\cdot) q^{\prime}(\cdot)$, is zero. Then the first-order condition becomes

$$
\left.\frac{\partial V_{m}}{\partial p_{m}}\right|_{p_{m}=0}=\hat{d}_{m}(0) \pi^{\prime}(0)>0
$$

Thus, the monopolist will charge a price higher than the competitive price in the aftermarket. The monopolist would like to commit to charge a competitive service price in all periods, thus maximizing the value of the equipment to the consumer. The monopolist could then extract the surplus through the monopoly equipment price. However, a monopolist that cannot make enforceable commitments will not charge marginal cost price in the aftermarket for the same reason a firm facing competition will not: once the firm has an installed base of consumers, the firm has an incentive to raise the price of service. ${ }^{27}$

27 In a related model of "open" vs. "closed" systems competition, Kende (1995) shows that when there is demand for variable quantities of equipment, and a taste for aftermarket variety, it will sometimes be in the monopolist's interest to maintain the aftermarket monopoly and extract some of the rents from product differentiation therein, rather than commit to a competitive service market. As in our model, welfare in Kende's system is always higher when the aftermarket is competitive. 
That is, in any continuation game starting with an installed base, the rational choice is to not charge $p=c$ in all future periods. Once again, this result is robust to our assumption that service price is constant across periods: any non-constant price path will necessarily have at least some periods with above-cost pricing.

Is the departure from competitive aftermarket pricing more severe for a monopolist than it is for duopolists? To address this question, we evaluate the monopolist's first-order condition at the duopolist's optimal service price,

$$
\left.\frac{\partial V_{m}}{\partial p_{m}}\right|_{p_{m}=p_{a}}=\hat{d}_{m}\left(p_{a}\right)\left[\pi^{\prime}\left(p_{a}\right)+\frac{\delta}{1-\delta} f^{\prime}(q) q^{\prime}\left(p_{a}\right)\right] .
$$

Using the fact that $\left(\phi^{\prime}+\pi^{\prime}\right)=f^{\prime}(\cdot) q^{\prime}(\cdot)$, the duopolist's first-order condition, equation (11), can be rewritten as

$$
\frac{\partial V_{a}}{\partial p_{a}}=\hat{d}\left(p_{a}\right)\left[\pi^{\prime}\left(p_{a}\right)+\frac{\delta}{1-\delta} \frac{2}{3} f^{\prime}(q) q^{\prime}\left(p_{a}\right)\right]=0 .
$$

The first-order conditions for the monopolist and duopolist have exactly the same form except for the coefficient of $2 / 3$ multiplying the marginal surplus in the oligopoly expression.

Why does only two-thirds of the marginal effect on consumer surplus enter the expression for the duopolist? Consider the effect of reducing service price: in the monopoly situation, gross consumer surplus from the service-augmented equipment increases. Because the marginal consumer is choosing between purchasing the equipment or not purchasing the equipment, the monopolist can capture, via the equipment price, the entire increase in surplus of the marginal consumer. The alternative available to the marginal customer offers zero surplus, and that alternative is fixed. In contrast, a duopolist is not able to capture the entire increase in consumer surplus to the marginal consumer from a reduction in the service price. Under duopoly, the marginal consumer is choosing between purchasing the equipment from the duopolist or from its competitor. As the duopolist captures more consumers, the marginal consumer it is attempting to capture is closer to the rival firm and receives greater surplus from the rival. Thus, it is increasingly difficult to capture market share as the marginal consumer that the duopolist faces obtains increasing surplus from her alternative purchase. 
Since the duopolist's market share is positive, $\hat{d}\left(p_{a}\right)>0$, the term in brackets in equation (20) must be equal to zero when evaluated at the duopolist's optimal price. We can use this fact to sign the monopolist's first-order condition evaluated at the duopoly service price. Since $f^{\prime}(q) q^{\prime}\left(p_{a}\right)$ is negative,

$$
\pi^{\prime}\left(p_{a}\right)+\frac{\delta}{1-\delta}\left[f^{\prime}(q) q^{\prime}\left(p_{a}\right)\right]<\pi^{\prime}\left(p_{a}\right)+\frac{\delta}{1-\delta} \frac{2}{3}\left[f^{\prime}(q) q^{\prime}\left(p_{a}\right)\right]=0 .
$$

That is, evaluated at $p_{a}$, the second term in the monopolist's first-order condition is negative. Then, since $\hat{d}_{m}\left(p_{a}\right)>0$, we know that the monopolist's first-order condition would be negative if it charged $p_{a}$ forever. That means it would make higher profits in a steady state in which it charged a price below the duopolist's optimal service price (assuming concavity of the value function). Thus, while the monopolist will exercise its market power over locked-in customers, in this model it will not do so to the same extent as an imperfectly competitive equipment firm. ${ }^{28}$

Now we discuss what happens if a customer is permitted to consider buying new equipment as an alternative to servicing old equipment. In the second period, a consumer weighs the gain to abandoning the used equipment and buying new to servicing the used equipment and using it for one more period. The consumer will service used equipment so long as

$$
s-\tau d-P_{m} \leq s-\tau d-h+f\left(q\left(p_{m}\right)\right)-p_{m} q\left(p_{m}\right)
$$

Suppose that at the optimal equipment and service prices derived above, where the firm did not consider that consumers might abandon used equipment to buy new, equation (22) did not hold. Then profits would not be maximized as consumers would never service equipment. The monopolist will set prices in each market such that inequality (22) just holds, in which case the equipment price will be given by

$$
P_{m}=h-f\left(q\left(p_{m}\right)\right)+p_{m} q\left(p_{m}\right) .
$$

\footnotetext{
28 The differing price between monopoly and duopoly may at first seem inconsistent with the claim in the previous section that the aftermarket price is independent of $\tau$ in the model. The $\tau$-irrelevance result holds so long as there is competition between the firms, i.e., the marginal customer for each firm gets positive consumer surplus from the product of the other firm. There is a change in equilibrium behavior at the point that $\tau$ (relative to the gross consumer surplus from consuming the service-augmented equipment) becomes large enough that the firms act as separate monopolists and each consumer buys either from one of the two firms or not at all.
} 
When buying new equipment is a viable alternative to servicing used equipment, the monopolist in essence has only one degree of freedom. Substituting (23) into the market boundary condition (13) and into the value function (14) leads to a new value function. It can be shown that, when evaluated at the service price implicitly given by (17), the new first-order condition would be negative. Thus, when new equipment is viable competition to serviced equipment, the monopolist reduces the price of service and the price of equipment. $^{29}$ Our main result continues to hold: if the monopolist charges a constant service price, that price will be higher than marginal cost.

\section{Conclusion}

Recent antitrust investigations of pricing and practices in aftermarkets have hinged on whether firms in reasonably competitive equipment markets could have an incentive to exercise market power in the associated aftermarkets. We have shown that, regardless of the structure of the equipment market, a firm that has market power over sales in its associated aftermarkets will exercise that power at least to some extent, pricing aftermarket goods and services above their competitive levels. The tradeoff between establishing a lowaftermarket-price reputation and extracting profits from locked-in customers will always result in elevation of price above the competitive level. This price elevation is likely to be greater when either high discount rates or a declining market lower the value of establishing a low-price reputation. Competition in the equipment market is more likely to discipline aftermarket prices when purchasing new equipment is a more viable alternative to servicing old equipment. Intuitively, this latter constraint is more binding when equipment is less durable - that is, when the net social surplus of servicing and re-using relative to producing a new unit of equipment is smaller.

The models we explore predict that it is only the inability to commit that leads to supracompetitive aftermarket pricing. It is easy to see why a perfect contractual commitment will typically be infeasible: the service life for durable equipment is often a decade

29 The latter can be seen as follows. First, denote the equipment and service prices that do not violate inequality (22) by $P_{m}^{\prime}$ and $p_{m}^{\prime}$. Because equation (22) is violated at the equipment and service prices characterized by (15) and (17), we know that $P_{m}>h-f\left(q\left(p_{m}\right)\right)+\pi\left(p_{m}\right)$. For the reasons given in the text, we know that the service price that does not violate $(22), p_{m}^{\prime}$, is less than the $p_{m}$. Therefore $f\left(q\left(p_{m}\right)\right)<f\left(q\left(p_{m}^{\prime}\right)\right)$ and $\pi\left(p_{m}\right)>\pi\left(p_{m}^{\prime}\right)$. Combining the above facts, we have $P_{m}>h-f\left(q\left(p_{m}\right)\right)+$ $\pi\left(p_{m}\right)>h-f\left(q\left(p_{m}^{\prime}\right)\right)+\pi\left(p_{m}^{\prime}\right)=P_{m}^{\prime}$. 
or more, there are many unverifiable dimensions of service quality, and cost changes are difficult to verify. ${ }^{30}$

Beyond the incentive to raise aftermarket prices through an exercise of market power, however, there are other reasons that a manufacturer might want to keep its aftermarkets closed. These range from quite defensible on public policy and antitrust grounds to rather suspect.

Shared liability - also known as the "finger pointing" problem - is perhaps the most defensible basis for excluding competitors from aftermarkets in those cases where it is supported by the evidence. If an outside vendor services the equipment or provides spare parts and the equipment then malfunctions, the equipment manufacturer might be falsely blamed for equipment failure that is actually due to low quality workmanship or parts from the outside vendor. The viability of this defense depends directly on the inability of the equipment manufacturers, consumers, or courts to sort out the correct cause of the equipment malfunction. ${ }^{31}$

Only slightly more controversial is the well-known "metering" explanation, charging high markups on the aftermarket product if consumption of that product is correlated with the surplus the consumer gets from the equipment. Oi (1971) and others have demonstrated that such pricing can raise profits in comparison to a marginal cost aftermarket price if consumers are heterogeneous. Such markups on the aftermarket product can be maintained, however, only if competitors are not allowed to enter the aftermarket. ${ }^{32}$

In our simple model of imperfect competition there is no role for metering or price discrimination through above-cost aftermarket prices. This is due to the assumption that gross consumer surplus and the cost of switching equipment brands - which is determined

30 We discuss problems with contractual commitments more fully in Borenstein, MacKie-Mason, and Netz (1995). An indirect approach to committing to downstream competitive pricing has been explored in the "second sourcing" literature; see, e.g., Shepard (1987) and Riordan and Sappington (1989). Kende (1995) has extended this literature by modeling the demand for variety in the aftermarket products.

31 The Supreme Court affirmed this argument in the Jerrold case, but the special factual circumstances of Jerrold have rarely been found in subsequent cases (Jerrold Electronics Corp. v. United States, 365 U.S. $567)$.

32 This is the standard explanation for IBM's insistence in the 1950s that consumers of its data processing machines use only punch cards purchased from IBM. 
by the parameter $\tau$ and the location of the consumer along the line - are uncorrelated with the intensity of use. These assumptions, however, often are not realistic. ${ }^{33}$ Higher intensity users may derive greater surplus from the machine and have larger costs of switching to another brand. When usage is correlated with surplus derived and/or the cost of switching between brands, metering can be used for price discrimination. ${ }^{34}$ Of course, as usual price discrimination has ambiguous social welfare consequences. ${ }^{35}$

There are other motivations for excluding aftermarket competition that may be less benign. An equipment firm with market power may want to exclude competition in the aftermarket in order to restrict competition in the equipment market, as such restrictions may reduce the threat of competition from used machines. The tying of complementary products to implement primary market foreclosure has been studied by Whinston (1990) and by Carlton and Waldman (1998). Many manufacturers charge high initial fees or outright refuse to provide service contracts on used equipment purchased from an independent broker. ${ }^{36}$ If the manufacturer is also the service monopolist, this strategy may effectively foreclose an independent market for used equipment. By reducing the supply of used equipment, the firm prevents the erosion of equipment market power.

Very closely related, manufacturers may want to monopolize an aftermarket in order to induce consumers to purchase new equipment or new models earlier than they otherwise would, effectively reducing the economic durability of the equipment. For example, a firm may be able to force consumers to move to the newest model of equipment by no longer

33 For an example of product differentiation that is correlated with intensity of use, consider the three sellers of high-volume copiers in the early years of that market: Kodak, Xerox and IBM. IBM specialized in copiers for the lower end of the high-volume market (50,000 - 100,000 copies per month). Kodak specialized in copiers for $100,000-500,000$ copies per month). Xerox specialized in very-high-volume copiers (300,000 - 1,000,000 copies per month).

34 Indeed, almost all high-volume copier service contracts have a base charge and a per copy ("click") charge. Clearly, service costs tend to vary with usage, but the click charge may be used for metering as well.

35 See Chen and Ross (1993) for a model in which firms with equipment market power use the aftermarket to implement price discrimination. Emch (1999) tests the metering theory and our theory, which he calls "opportunism," in the printer toner and printer memory markets. He finds some support for the opportunism theory.

36 This was one of the allegations in the Kodak case, for example. 
servicing old models of equipment. This effect will not obtain if service is available from other vendors. ${ }^{37}$

Finally, exclusion of aftermarket competition may be motivated by the desire to influence the flow of information to customers. This is known in the industry as "account control": regular visits from the manufacturer's field technicians can be used to influence future equipment upgrade and expansion decisions. Service provision by an independent technician may provide the customer with a low cost source of independent information on the advantages of alternative brands for future purchases.

All of these reasons for exclusion of aftermarket rivals have been supported by evidence in various cases over the last decade. Some may be harmful to consumers while others may be pro-competitive. Nonetheless, we have shown that once competition in the aftermarket is excluded, a profit maximizing firm will not maintain competitive prices in the aftermarket regardless of the degree of competition in the equipment market.

37 For example, manufacturers often raise parts prices on older equipment to induce upward migration. 


\section{References}

Beggs, Alan and Paul Klemperer (1992) "Multi-Period Competition with Switching Costs," Econometrica, 60(3), 651-66.

Borenstein, Severin, Jeffrey K. MacKie-Mason and Janet S. Netz (1995) "Antitrust Policy in Aftermarkets," Antitrust Law Journal, 63(2), 455-482.

Carlton, Dennis W. and Michael Waldman (1998) "The Strategic Use of Tying to Preserve and Create Market Power in Evolving Industries," NBER Working Paper 6831, Cambridge, MA, December.

Chen, Zhiqi and Thomas Ross (1993) "Refusals to Deal, Price Discrimination, and Independent Service Organizations," Journal of Economics \& Management Strategy, 2(4), 593-614.

Chen, Zhiqi and Thomas Ross (1999) "Refusals to Deal and Orders to Supply in Competitive Markets," International Journal of Industrial Organization, 17(3), 399-417.

Emch, Eric (1999) "Pricing in Durable Goods Aftermarkets: Theory and Evidence," Ph.D. Dissertation, University of California at Berkeley.

Farrell, Joseph and Carl Shapiro (1987) "Dynamic Competition with Switching Costs," Rand Journal of Economics, 19(1), 123-37.

Farrell, Joseph and Carl Shapiro (1989) "Optimal Contracts with Lock-In," American Economic Review, 79(1), 51-68.

Kende, Michael (1998) "Profitability under an Open versus a Closed System," Journal of Economics and Management Strategy, 7(2), 307-26.

Klein, Benjamin (1993) "Market Power in Antitrust: Economic Analysis after Kodak," Supreme Court Economic Review, 3, 43-92.

Klein, Benjamin and Keith B. Leffler (1981) "The Role of Market Forces in Assuring Contractual Performance," Journal of Political Economy, 89(4), 615-641. 
Klemperer, Paul (1987) "The Competitiveness of Markets with Switching Costs," Rand Journal of Economics, 18(1), 138-50.

MacKie-Mason, Jeffrey K. and John Metzler (1998) "Links Between Vertically Related Markets: ITS v. Kodak," in The Antitrust Revolution, ed. J. Kwoka and L. White. Oxford, UK: Oxford University Press.

Oi, Walter (1971) "A Disneyland Dilemma: Two-Part Tariffs for a Mickey Mouse Monopoly," Quarterly Journal of Economics, 85(1), 77-96.

Riordan, Michael H. and David E.M. Sappington (1989) "Second Sourcing," Rand Journal of Economics, 20(1), 41-58.

Shapiro, Carl (1982) "Consumer Information, Product Quality, and Seller Reputation," Bell Journal of Economics, 13, 20-35.

Shapiro, Carl (1995) "Aftermarkets and Consumer Welfare: Making Sense of Kodak," Antitrust Law Journal, 63(2), 483-512.

Shepard, Andrea (1987) "Licensing to Enhance Demand for New Technologies," Rand Journal of Economics, 18, 360-368.

Whinston, Michael D. (1990) "Tying, Foreclosure and Exclusion," American Economic Review, 80, 837-859. 


\section{Appendix}

\section{AFTERMARKET MARKET POWER WITH PERFECTLY COMPETITIVE EQUIPMENT MARKETS}

In this appendix, we consider the incentive of perfectly competitive equipment firms to exercise market power in the aftermarket. The case law includes many allegations that competition in the equipment market prevents the firm from exercising market power in the aftermarket. We consider the most extreme form of competition in equipment - perfect competition - and find that perfectly competitive equipment firms do exercise market power in the aftermarket. Indeed, depending on the parameter values, the perfectly competitive equipment firm may find it optimal to charge a monopoly price over service.

We follow the notation, terminology, and assumptions used in our differentiated duopoly model when possible. Consider the markets for some durable good - which we will call "equipment" - and an associated aftermarket product - which we will call "service." In period $t$, a consumer buys either one or zero units of equipment. In period $t+1$ she will have a demand function for service, given by $q(p)$. The equipment lasts at most two periods.

We assume that there is a free-entry, perfectly competitive market for the equipment, but that the equipment manufacturer is the only seller of the service associated with its brand. Thus, after buying and using equipment in period $t$, in period $t+1$ the consumer can (1) use the product in its depreciated state with no addition of service, (2) buy some quantity of service from the same seller to enhance the equipment, or (3) re-enter the equipment market. The equipment and service products each have constant unit production costs, $C$ and $c$ respectively, identical for all firms.

All consumers are identical ex ante and they consider equipment from different manufacturers to be homogeneous ex ante. We assume that consumers have completely inelastic unit-demand for equipment. That is, so long as the price is below the consumer's value of 
the equipment, she will purchase one unit. ${ }^{38}$ They receive gross surplus from owning the equipment, $C S^{1}=s$ for a new product and $C S^{2}=s-h+f(q)$ for a period-old product that has been augmented with $q$ units of service, where $h$ represents the depreciation in the value of the product from one period of use. The function $f(\cdot)$ is simply the integral of the inverse demand for service with $f(0)=0, f^{\prime}(\cdot)>0$, and $f^{\prime \prime}(\cdot)<0$.

To make the analysis informative, we assume that (1) $s-h+f(q(c))-c q(c)>s-C$ for some $q \geq 0$ and $(2) f^{\prime}(0)>c$. The first assumption ensures that re-using the period-old product would be preferred to buying a new unit each period if both the new equipment and service were priced at cost. ${ }^{39}$ The second assumption assures that purchase of at least a small quantity of service would give positive net consumer surplus if it were priced at cost. Together, the two assumptions imply that the first-best solution in this market is for consumers to use each unit of the equipment for two periods and to purchase some positive quantity of service in the second period. For simplicity, we also assume that $s \geq C$. This assures that, if equipment is priced at cost, each consumer will purchase one unit of equipment.

\section{A1. The Two-Period Model}

We first solve the model in a two-period context. This allows us to demonstrate the generic inefficiencies that can result from the absence of competition in the aftermarket. In this model each firm must choose three variables: first-period equipment price, secondperiod service price, and second-period equipment price.

Consider the second period when each firm must simultaneously choose a price for service and a price for new equipment. If there were no link between the markets for service and for new equipment, a monopolist would maximize service profits in period two by finding the monopoly price $p_{m}=\arg \max _{p}(p-c) q(p)$. However, the aftermarket monopolist must account for the constraint that at a sufficiently high service price, equipment owners

\footnotetext{
38 We assume completely inelastic demand to be consistent with the imperfect competition model developed in the paper. The basic results are unchanged when demand is downward-sloping, except as noted in the final paragraph of section A1.

39 Purchasing a new unit each period would generate net consumer surplus of $s-C$ every period. Servicing the used units would replace every other $s-C$ with surplus of $s-h+f(q(c))-c q(c)$.
} 
will abandon their used equipment and buy new. From the strict inequality in assumption (2) and assuming continuity of the consumer surplus functions, we know that there are prices $p>c$ at which consumers will choose to buy a positive quantity of service. Similarly, there is some price $\bar{p}$ at which consumers are indifferent between buying a new equipment unit or enhancing the period-old unit; $\bar{p}$ is defined implicitly by

$$
s-P^{2}=\max _{\bar{p}} s-h+f(q(\bar{p}))-\bar{p} q(\bar{p}),
$$

where $P^{2}$ is the second-period price of new equipment. Thus, the seller sets service price to maximize monopoly profits subject to the constraint that service price cannot be so high as to drive consumers to re-enter the equipment market: $p^{*}=\min \left(p_{m}, \bar{p}\right)$.

Because the equipment market is perfectly competitive and entry is costless, we know that $P^{2}$ can be no greater than $C$. Because period two is the last period and the equipment sold in period two will never require service, no firm would ever want to sell a unit at $P^{2}<C$. Thus, the price of equipment in the second period will be $P^{2}=C$. ${ }^{40}$ Plugging $P^{2}=C$ into equation $(A 1)$ gives $\bar{p}$ implicitly.

How does $p^{*}$ compare to cost? If the unconstrained monopoly price is below the level at which consumers would abandon their used equipment and buy new, so that $p^{*}=p_{m}$, then the service price will of course be above cost as in a standard monopoly, giving the familiar monopoly deadweight loss. ${ }^{41}$ If $p^{*}=\bar{p}$, then assumption (1) assures that $\bar{p}>c$. Thus, the price of service in period two will exceed cost, and firms will earn profits in period two.

In period one, each of the perfectly competitive sellers realizes that in period two it will be able to make profits of $\pi^{2}=\left(p^{*}-c\right) q\left(p^{*}\right)$ by providing service for each unit sold in period one. Free entry implies that the firms break even overall, so the equilibrium price

\footnotetext{
40 Suppose that new consumers enter the equipment market in the final period; because this is the final period, these consumers will use the equipment for only one period and will never service the equipment. Then $P^{2}=C$ is the only Nash equilibrium. Alternatively, if the only possible equipment buyers in the final period are consumers who abandon their used equipment, there are Nash equilibria in which all firms charge the same equipment price below cost and price service at the price implicitly defined in equation $(A 1)$. However, $P^{2}=C$ strictly dominates $P^{2}<C$. We rule out dominated strategies.

41 Consumers will continue to purchase service at the monopoly price so long as $s-C<s-h+f\left(q\left(p_{m}\right)\right)-$ $p_{m} q\left(p_{m}\right)$.
} 
for the equipment would be $P^{1}=C-\delta \pi^{2}=C-\delta\left(p^{*}-c\right) q\left(p^{*}\right)$, where $\delta$ is the discount factor. Thus, the first period equipment price is below cost.

Though the competitive firms earn zero profits, the equilibrium creates deadweight loss in comparison to the outcome that obtains if both equipment and service are sold in competitive markets. In period one, the gain in consumer surplus in the equipment market from below-cost pricing is exactly equal to the loss in producer profits. ${ }^{42}$ In period two, however, the loss in consumer surplus from above-cost service pricing is greater than the associated profit gain since consumers reduce their purchase of service in the face of a higher service price. Thus, if overall profits remain at zero, consumer surplus over the two-period lifetime of the equipment must fall relative to the outcome with competition in both markets. The result is inefficient underconsumption of service in period two. ${ }^{43}$

\section{A2. The Discrete-Period Finite Horizon Equilibrium}

We continue to assume that equipment lasts at most two periods and we suppose that there are new customers every period. Competition for these new customers determines the equipment price. Each period the firm sets a service price for those customers who purchased equipment in the previous period. As in the two-period model, the firm is an ex post monopolist with respect to service prices and it is constrained by the threat that if service prices are too high, consumers will abandon their old equipment and buy new at prices set in the competitive equipment market. We assume that information is complete, and that when consumers purchase equipment, they rationally anticipate the

42 Given our demand structure for new equipment, deviations from marginal cost pricing cannot affect the quantity of sales of new equipment. We assumed that $s \geq C$, so that if equipment is priced at cost, all consumers buy equipment. As the price of equipment falls below cost, all consumers continue to buy equipment. Suppose that $s<C$. Then consumers will purchase equipment only if the surplus from using the equipment for two periods is positive. If the two-period net consumer surplus is negative when the products are priced at cost, then no set of sustainable prices exists under which the consumer would purchase equipment. Suppose that the two-period net consumer surplus is positive when the products are priced at cost. If firms wish to make any sales, two-period consumer surplus must remain positive, so all consumers continue to purchase equipment as prices deviate from cost. Under a more general demand curve, as prices deviate from cost it is possible that consumers will reduce purchases of equipment because, as explained in the text, two-period net consumer surplus declines as prices deviate from cost.

43 The consumer surplus if both goods were sold in perfectly competitive markets would be $C S=$ $s-C+\delta[s-h+f(q(c))-q(c) c]$. In the equilibrium with a monopoly service market, $C S=\max (0, s-$ $\left.\left[C-\delta q\left(p^{*}\right)\left(p^{*}-c\right)\right]+\delta\left[s-h+f\left(q\left(p^{*}\right)\right)-q\left(p^{*}\right) p^{*}\right]\right)$. Assuming that the equipment is purchased in both cases, the consumer surpluses differ by an amount equal to the discounted deadweight loss "triangle" in the service market that occurs when $p^{*}>c$. 
firm's strategy for pricing service. Since the game is finite, all of the actors solve backwards by recursion for the equilibrium.

In each period, the optimal service price is determined as in the two-period model: the firm sets price as close to the unconstrained monopoly level as possible without inducing consumers to abandon used equipment. For the monopoly service price to obtain, it is necessary that consumer surplus from servicing old equipment be at least as large as consumer surplus from buying new in the competitive equipment market:

$$
\begin{aligned}
s-h+f\left(q\left(p_{m}\right)\right)-p_{m} q\left(p_{m}\right) & \geq s-P \\
& \Rightarrow c s\left(p_{m}\right) \geq h-P,
\end{aligned}
$$

where $p_{m}$ denotes the unconstrained monopoly service price and $c s(x) \equiv f(q(x))-x q(x)$ denotes net consumer surplus in the service market at price $x$. If condition $(C 1)$ does not hold, the firm is disciplined, to some extent, by the existence of a competitive equipment market. In this case, the service price is set to leave the consumer the same consumer surplus whether servicing used equipment or buying new equipment. Then $p$ is implicitly determined by

$$
\begin{aligned}
s-h+f(q(p))-p q(p) & =s-P \\
& \Rightarrow c s(p)=h-P .
\end{aligned}
$$

From both equations it is clear that determination of the equilibrium service price depends on the equilibrium equipment price, to which we now turn.

In period $N$, the dominant strategy is to price equipment at cost by the same reasoning as in the two-period model. Derivation of the previous periods' equipment prices hinges on the fact that each firm must earn zero profits on each generation of customers, given free entry. Thus, given profits earned in the service market the following period of $\pi^{N-t+1}$ on any equipment sold in period $N-t$, free entry guarantees that

$$
P^{N-t}=C-\delta \pi^{N-t+1} ;
$$

that is, free entry drives the equipment price below cost by the discounted value of profits to be earned from service so that profits overall are zero. 
Returning to the equilibrium service price, the condition for the monopoly service price to obtain in the final period, given an equipment price equal to $C$, is given by

$$
c s\left(p_{m}^{N}\right) \geq h-C .
$$

If condition $\left(C 1^{\prime}\right)$ holds, then the monopoly service price holds in the final period. If not, the service price is set such that $\operatorname{cs}\left(p^{N}\right)=h-C$ holds.

In earlier periods, the condition under which the monopoly service price obtains is given by

$$
c s\left(p_{m}^{N-t}\right) \geq h-C+\delta \pi^{N-t+1}
$$

since the equipment price in previous periods is below cost. This is a tighter restriction than condition $\left(C 1^{\prime}\right)$ : the lower is the price of new equipment, the more surplus the consumer must be left with if she services used equipment to prevent the consumer from buying new. ${ }^{44}$

Four equilibria are possible, depending on parameter values. First, condition $\left(C 1^{\prime}\right)$ may not hold. In this case, the service price is constrained in all periods. Alternatively, condition $\left(C 1^{\prime}\right)$ may hold while condition $\left(C 1^{\prime \prime}\right)$ does not. Then the monopoly service price obtains in the final period, but the existence of a competitive equipment market constrains the firm in setting its service price in the penultimate period. In previous periods, two possibilities arise, depending on whether condition $C 1^{\prime \prime}$ holds in period $N-2$. If not, then it also will not hold in any previous period, and the price in all periods except the last will be constrained by the competitive equipment market. Suppose that condition $C 1^{\prime \prime}$ does hold in period $N-2$, given the service profits to be earned in period $N-1$. Then the firm will set the monopoly service price in $N-2$. The service price in $N-3$ will be derived as it is in $N-1$, and a two-state price cycle arises. The service price is driven below the monopoly level in half the periods and is set at the monopoly level in the remaining periods. Finally, if condition $\left(C 1^{\prime \prime}\right)$ holds, then the monopoly service price will obtain in all periods. The existence of a competitive equipment market will not discipline the service price at all, though it will ensure that firms earn zero profits overall.

44 Thus, it follows that if the monopoly service price does not obtain in period $N$, that is condition $\left(C 1^{\prime}\right)$ does not hold, neither will $\left(C 1^{\prime \prime}\right)$, and the monopoly service price will not hold in any period. 
To summarize, the equilibrium equipment price is given by

$$
P^{N-t}= \begin{cases}C & t=0 \\ C-\delta \pi^{N-t+1} & t>0 .\end{cases}
$$

The equilibrium service price depends on parameter values.

- Case A: $\operatorname{cs}\left(p_{m}\right)<h-C$

$$
\begin{array}{ll}
c s\left(p^{N}\right)=h-C \Rightarrow p^{N}, & t=0 \\
c s\left(p^{N-t}\right)=h-C+\delta \pi^{N-t+1} \Rightarrow p^{N-t}, & t>0
\end{array}
$$

- Case B: $h-C \leq c s\left(p_{m}\right)<h-C+\delta \underline{\pi}$

$$
\begin{aligned}
& p^{N}=p_{m} \\
& c s\left(p^{N-t}\right)=h-C+\delta \pi^{N-t+1} \Rightarrow p^{N-t}, \quad t>0
\end{aligned}
$$

- Case C: $h-C+\delta \underline{\pi} \leq c s\left(p_{m}\right)<h-C+\delta \pi_{m}$

$$
\begin{array}{lr}
p^{N-t}=p_{m}, & t=0,2,4,6, \ldots \\
c s\left(p^{N-t}\right)=h-C+\delta \pi_{m} \Rightarrow p^{N-t}, & t=1,3,5,7, \ldots
\end{array}
$$

- Case D: $h-C+\delta \pi_{m} \leq c s\left(p_{m}\right)$

$$
p^{N-t}=p_{m}, \quad t \geq 0,
$$

where $\underline{\pi}$ is determined by the $\underline{p}$ that is implicitly defined by $\operatorname{cs}(\underline{p})=h-C+\delta \pi_{m}$. For prices greater than $\underline{p}$, condition $C 1^{\prime \prime}$ does not hold, while for prices less than or equal to $\underline{p}$, condition $C 1^{\prime \prime}$ does hold.

Analysis of the equilibria leads immediately to the key feature of the pricing structure: in all cases, both equipment and service prices are not equal to cost. The service price in all periods is greater than cost, while the equipment price is below cost in all but the $N$ th period. Thus, the welfare result from the two-period model carries over: firms earn zero profits overall, but the equilibrium creates a deadweight loss compared to an industry in which prices are always set equal to marginal cost.

To demonstrate that the equilibrium service price is above cost, we show that $c s(c)>$ $c s\left(p^{N-t}\right)$ when the service price is constrained by the existence of a competitive equipment 
market. ${ }^{45,46}$ For expositional ease, re-state assumption (1) as $c s(c)=h-C+\Delta$, where $\Delta$ is positive. The equilibrium service price is higher than cost if consumer surplus evaluated at the equilibrium service price is less than consumer surplus evaluated at cost (that is, if $\left.c s\left(p^{N-t}\right)<c s(c)\right)$. Substituting for $c s(c)$ using assumption (1) and substituting for $c s\left(p^{N-t}\right)$ using the equilibrium condition for service price, the condition under which service price is above cost can be written as $h-C+\Delta>h-C+\delta \pi^{N-t+1}$, or $\Delta>\delta \pi^{N-t+1}$.

Consider whether the condition holds in period $N$. Because the service price is constrained away from the monopoly price, it is set such that the consumer receives the same net surplus she would if she abandoned the used equipment and bought new. From Case A above, the consumer surplus from service would then be $\operatorname{cs}\left(p^{N}\right)=h-C$. Therefore, the change in consumer surplus as the price rises from $c$ to $p^{N}$ is given by $\operatorname{cs}(c)-\operatorname{cs}\left(p^{N}\right)=$ $h-C+\Delta-(h-C)=\Delta$. The firm will be unable to appropriate the entire change in consumer surplus as price rises since consumers will reduce purchases of service; thus, profits from service in period $N$ will be less than $\Delta$. Since $\delta<1, \delta \pi^{N}<\pi^{N}<\Delta$. Therefore the equilibrium service price is above cost in period $N$.

The condition $\left(\Delta>\delta \pi^{N-t+1}\right)$ holds in previous periods because $p^{N-t} \leq p^{N}, \forall t$. This follows as firms compete by lowering the equipment price to attract customers from whom the firm can profit from service in the following period. The lower is the equipment price, the lower must be the service price in that period to prevent consumers from abandoning used equipment. Given lower service prices, profits too must be smaller than in period $N$, so $\delta \pi^{N-t} \leq \delta \pi^{N}<\Delta \forall t$. Thus, the equilibrium service price is above cost in all periods and the equipment price is below cost in all periods except period $N$.

The equilibria price paths offer several insights. First, note that the firm is most constrained by the existence of a competitive equipment market in Case A, mostly constrained in Case B, somewhat constrained in Case C, and completely unconstrained in Case D. The degree of constraint is determined simply by the surplus a consumer receives when servicing equipment at the monopoly service price versus abandoning the equipment and buying

\footnotetext{
45 Given assumption (2), price is above cost whenever the monopoly service price obtains.

46 That the equipment price is less than cost is self-evident once we show that profits in the service market tomorrow from sales of equipment today are positive, or in other words that the service price is always above cost.
} 
new in the competitive equipment market. The bigger the gain to servicing and re-using equipment relative to buying new, the more discretion the firm has to exercise its monopoly position in the service market.

The conditions can be re-written in terms of $h-C .{ }^{47}$ The term $h-C$ is the social net cost to re-using equipment: re-use costs $h$ in depreciation, but saves the cost of producing a new unit of equipment, $C$. The higher is the cost to re-using the equipment, the smaller the ability of the firm to charge high service prices. When a machine is serviced in the second period, the service provider can charge for the service value-added, but must take into account the cost of re-using the equipment $(h-C)$. Thus, the service price increases as the cost to re-using equipment declines. When the cost to re-use is sufficiently small, the firm can charge the monopoly service price. This is true because the surplus obtained from service is inframarginal with respect to the efficient decision whether to re-use the equipment or discard it. The service provider can charge the monopoly service price and there will still be some re-use surplus left over, ensuring that consumers will not abandon old equipment prematurely.

Alternatively, $h-C$ can reasonably be interpreted as an inverse measure of durability: equipment is more durable the smaller is depreciation relative to the cost of producing a new unit of equipment. Then as equipment becomes more durable, the firm is less constrained by the existence of a competitive market for new equipment since new equipment essentially becomes a less good substitute for service. To the extent that this notion of durability generalizes, we expect that service prices will be higher, and the resulting allocative inefficiencies greater, the more durable is the original equipment. Alternatively, the model can be interpreted as a model of switching costs. Before adding service, the switching cost between used and new equipment is captured by $C-h$, the cost of new equipment less the gain in foregone depreciation. As the switching cost increases $(h-C$ decreases), the more market power the firm can exercise over service. Indeed, once the switching cost increases sufficiently, the option to switch to new equipment is so costly that it does not discipline the price of service at all.

47 Specifically, Case A arises if $c s\left(p_{m}\right)<h-C$; Case B if $c s\left(p_{m}\right)-\delta \underline{\pi}<h-C \leq c s\left(p_{m}\right)$; Case C if $c s\left(p_{m}\right)-\delta \pi_{m}<h-C \leq c s\left(p_{m}\right)-\delta \underline{\pi}$; and Case D if $h-C \leq c s\left(p_{m}\right)-\bar{\delta} \pi_{m}$. 


\section{A3. The Discrete-Period Infinite Horizon Equilibrium}

In the infinite-horizon setting, it is easy to show the central result without a complete characterization of the (possibly multiple) equilibria: no equilibrium of the infinite-horizon problem exists in which the service and equipment prices are set equal to marginal cost in every period.

The argument is simple: Due to free entry and complete information, in equilibrium firms earn zero profits as of any stage of the game. Consider then a firm that deviates from marginal cost pricing in period $t$ : by charging $p^{t}>c$ and $P^{t} \geq C$ it can earn positive profits in that period. ${ }^{48}$ Since there are no costs to exit the industry in our model, the worst punishment that the consumers and other sellers can impose is to force the deviant producer to exit. However, since the discounted value of its profits are now positive, this strategy dominates marginal cost pricing in every period, which yields the result.

\section{A4. Conclusion}

The perfect competition model is designed to present the strongest case for equipment markets that might discipline aftermarkets: there are no switching costs between equipment brands; consumers have complete information; and entry is free into homogeneous equipment production. Our results are intuitive and robust: even a perfectly competitive equipment market at best only partially disciplines the service market; depending on parameter values, it may not discipline the service market at all.

\footnotetext{
48 Assumption 1 assures that even when new equipment is available at cost, the consumer will receive positive net surplus when service is priced at cost. Therefore the firm can raise the service price above cost at least a little without inducing consumers to abandon old equipment and to buy new.
} 